1 Irvine AE, Morris TCM, Kelly GT, McCracken N. Ticarcillin-induced neutropenia corroborated by in vitro CFU-C toxicity. Acta Haematol 1983;70:364-8. 2 Bradley PP, Warden GD, Maxwell JG, Rothstein G. Neutropenia and thrombocytopenia in renal allograft recipients treated with trimethoprim-sulfamethoxazole. Ann Intern Med 1980;93:560-2.

3 Asmar BI, Maqbool S, Dajani AS. Hematologic abnormalities after oral trimethoprim-sulfamethoxazole therapy in children. Am $\mathcal{F}$ Dis Child 1981;135:1100-3.

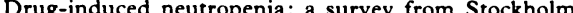
1973-78. Acla Med Scand 1982;212:289-92.

Rouveix B, Lassoued K, Vittecoq D, Regnier B. Neutropenia due to $\$$ lactamine Br $1983 ; 287: 1832-4$.

(Accepted 2 fanuary 1985)

Northern Ireland Leukaemia Research Fund, Department of Haematology, Queen's University, Belfast

A E IRVINE, BSC, PHD, senior scientific officer

Department of Haematology, Belfast City Hospital, Belfast BT9 7AD A N D AGNEW, $\mathrm{MB}, \mathrm{BCH}$, registrar, haematology laboratory

T C M MORRIS, MD, MRCPATH, consultant haematologist

Correspondence to: Dr T C M Morris.

\section{Air in the bones: multifocal anaerobic osteomyelitis associated with oat cell carcinoma}

Under $2^{\circ}{ }^{\circ}$ of cases of osteomyelitis are due to anaerobes. ${ }^{1}$ We report a case of multifocal anaerobic osteomyelitis complicating widespread bone metastases from an oat cell carcinoma of the lung.

\section{Case report}

A 60 year old white man was admitted with low back pain, $10 \mathrm{~kg}$ weight loss, and bilateral leg oedema. He was a heavy smoker and drinker. He was afebrile with signs of chronic alcoholism and bilateral leg oedema. Oral hygiene was poor. His liver was firm and enlarged. His lumbar vertebrae and pelvic bones were painful on percussion. White cell count was $22 \cdot 3 \mathrm{X}$ $10^{9} / 1\left(68^{\circ}\right.$ segmented). A chest $x$ ray film showed a $2 \mathrm{~cm}$ nodule.

Computed tomography showed bilateral abscesses along the psoas and the iliac muscles and gas in the pelvic bones, T5, T6, L1, L4, L5, and the spinal canal (figure). Areas of osteolysis as well as gas were detected on $x$ ray films

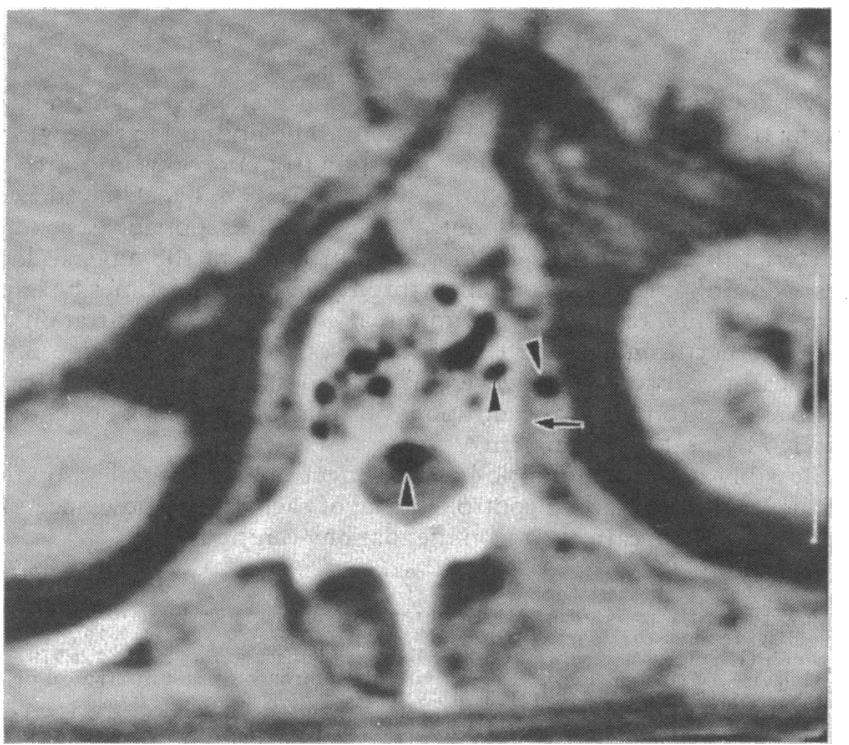

Computed tomogram of $\mathrm{L} 1$, showing gas bubbles within vertebral body, spinal canal, and psoas muscles (vertical arrows); psoas abscesses are seen along lateral aspect of vertebral body (horizontal arrow).

of the thoracic and lumbar spine and the pelvic bones. Metastases were seen in the liver. Bone marrow aspirate from the iliac crest was foul smelling, and Gram staining showed abundant Gram positive cocci. The bone marrow and eight blood cultures were positive for Peptococcus indolicus. Intravenous penicillin was started. He died on the 34 th hospital day.
At necropsy a small cell carcinoma of the lung was found with metastases in the bones, liver, and lymph nodes. The sites of osteomyelitis corresponded with $x$ ray findings; histological examination of bone showed large areas of necrosis surrounded by inflammatory cells within foci of metastatic small cells. Bilateral psoas abscesses were present.

\section{Comment}

Anaerobic osteomyelitis results from invasion of the bones by organisms responsible for infection in an adjacent area. ${ }^{2}$ It is a rare complication of anaerobic bacteraemia: of 1280 patients reported on in review articles on anaerobic bacteraemia, only seven developed osteomyelitis. $^{3}$ These clinical data are corroborated by experimental studies, which have shown it to be extremely difficult to establish infection with normally saprophytic organisms in uninjured bone. ${ }^{4}$

Given the low incidence of bone infection in anaerobic bacteraemia, predisposing factors may play a major part when it occurs. Of the underlying systemic diseases, haemoglobinopathies and malnutrition (which affect tissue oxidation potential) have been associated with haematogenous osteomyelitis. ${ }^{2} 4$ Any condition (anaemia, ischaemia, diabetes, or malignancy) that favours disruption of normal capillary flow, however, will result in a decrease in perfused tissue oxidation potential and predispose to replication of anaerobes. ${ }^{4}$ Although bone metastasis seems an ideal environment for anaerobic growth, its association with anaerobic osteomyelitis has not been reported previously. We have found only two reports of patients with anaerobic multifocal osteomyelitis ${ }^{3}$; interestingly, one of these was a child with acute lymphocytic leukaemia and bilateral femoral osteomyelitis due to bacteroides.

The diagnosis was suspected in our patient because of the presence of gas within bones on standard $x$ ray films and a computed tomogram. Gas was even seen in the spinal canal and within bilateral paraspinal muscle abscesses. Detection of gas associated with osteomyelitis has recently been reported $^{5}$; this phenomenon is probably not uncommon, as it is well known that anaerobes can produce gas.

We thank Professor A F Muller, Professor F Waldvogel, Dr P Deleamont, Dr O Louis, and Dr R Lagier for reviewing the manuscript and their helpful discussions, and Mrs C Todisco for secretarial help.

1 Waldvogel FA, Medoff G, Swartz MN. Osteomyelitis: a review of clinical features, therapeutic considerations and unusual aspects. $N$ Engl $\mathcal{F}$ Med 1970;282:198-

2 Templeton WC III, Warukiewics A, Melo JC, Schiller MG, Raff MJ. Anaerobic osteomyelitis of long bones. Rev Infect Dis 1983;5:692-712.

3 Raff MJ, Melo JC. Anaerobic osteomyelitis. Medicine (Baltimore) 1978;57:83-103. Ogden JA, Light TR. Pediatric osteomyelitis. III. Anaerobic microorganisms. Clin Orthop $1979 ; 145 \cdot 230-6$

5 Ram PC, Martinez S, Karobkin M, Breiman RS, Gallis HR, Harrelson JM CT detection of intraosseous gas: a new sign of osteomyelitis. Am $\exists$ Radio $1981 ; 137: 721-3$.

(Accepted 30 fanuary 1985)

Clinique Médicale and Division des Maladies Infectieuses, Department of Medicine, and Department of Radiology, University Hospital of Geneva, Switzerland

JACQUES PHILIPPE, MD, medical resident ESMAIL SHEYBANI, MD, medical intern

BERNARD HIRSCHEL, MD, research fellow in infectious diseases BERNARD ODY, MD, radiology consultant

Correspondence to: Dr J Philippe, Laboratory of Molecular Endocrinology, Massachusetts General Hospital, Boston, Mass 02114, USA.

\section{Peritonitis due to Streptococcus viridans in patients receiving continuous ambulatory peritoneal dialysis}

Vas suggested that peritonitis in patients receiving continuous ambulatory peritoneal dialysis may result from haematogenous spread of bacteria from lesions in the mouth. ${ }^{1}$ We report on four patients receiving continuous ambulatory peritoneal dialysis who developed peritonitis due to Streptococcus viridans after having oral lesions or undergoing dental surgery. 